\title{
Simple quality control technique to identify dissolved oxygen diffusion issues with biochemical oxygen demand bottle incubations
}

\author{
Johnathan Daniel Maxey*, Neil David Hartstein, Dorathy Penjinus and Alan Kerroux \\ Aquadynamic Solutions Shd. Bhd., Lot G3/3 Ground Floor, Block B, Wisma Manikar, Lorong Manikar 1, Off Mile 2.5 \\ Jalan Tuaran, Likas, 88400 Kota Kinabalu, Sabah, Malaysia
}

*Corresponding author: jdm@aquadynamicsolutions.net

\begin{abstract}
Stratified estuaries are home to expanding aquaculture activities whose ecological footprints can be observed through trends in microbial community respiration in the water column. Bottle incubations are widely used to measure water column community respiration in marine and freshwater ecosystems by measuring the flux of dissolved oxygen occurring in the bottle over a period of time. When in situ dissolved oxygen (DO) concentrations are markedly different than DO concentration of the incubation medium the potential for diffusion of oxygen across the bottle opening is great and may be especially pronounced in strongly stratified systems with relatively low rates of pelagic oxygen consumption. We incubated 60 Biochemical Oxygen Demand (BOD) bottles filled with sterilized water with DO concentrations ranging from $2.51 \mathrm{mg} \mathrm{O}_{2} \mathrm{~L}^{-1}$ to $10.03 \mathrm{mg} \mathrm{O}_{2} \mathrm{~L}^{-1}$ for 24 hours in a temperature controlled water bath. There was a significant relationship when DO flux was set as a function of initial DO (DO Flux $=-0.0017 \mathrm{x}+0.0085, \mathrm{r}^{2}=0.72, \mathrm{p}<2.2 \mathrm{e}^{-16}$ ). DO fluxes ranged from $-0.012 \mathrm{mg} \mathrm{O}_{2} \mathrm{~L}^{-1}$ hour-1 to $0.005 \mathrm{mg} \mathrm{O}_{2} \mathrm{~L}^{-1}$ hour-1 for bottles incubated with initial D0 ranging from $10.03 \mathrm{mg} \mathrm{O}_{2} \mathrm{~L}^{-1}$ to $3.31 \mathrm{mg} \mathrm{O}_{2} \mathrm{~L}^{-1}$, respectively. These results suggest that diffusion across the ground glass seal of BOD bottles is possible and that extra precaution through parallel diffusion controls should be considered when measuring pelagic respiration using BOD bottle incubations in systems with relatively low or relatively high in situ DO concentrations.
\end{abstract}

Keywords: Aquaculture impacts, Pelagic community, Dissolved oxygen, Environmental monitoring

\section{Introduction}

Bottle incubations have been used for nearly 100 years to quantify community respiration in the water column (Robinson and Williams, 2005; Williams and del Giorgio, 2005). Several factors affect the rate of community respiration such as temperature, organic matter supply, organic matter quality, and community composition. Aerobic respiration supports higher rates of organic matter oxidation and when dissolved oxygen (hereafter referred to as "DO") is no longer sufficient to support aerobic respiration, alternate metabolic pathways utilizing other electron acceptors (such as $\mathrm{NO}_{3}{ }^{-}, \mathrm{Mn}^{2+}, \mathrm{SO}_{4}, \mathrm{Fe}^{2+}$ ) may be used to complete respiration albeit at lower rates of carbon oxidation (Valiela, 2013). Marine ecologists, ecosystem monitors and aquaculture managers are not only interested in respiration as an important driver of carbon dynamics, but also as a driver of DO dynamics in aquatic systems as water column hypoxia is a burgeoning worldwide concern (Rabalais et al., 1999; Diaz and Rosenberg, 2008; Conley et al., 2009). Many efforts to quantify community respiration in marine systems rely on measurements of DO (Robinson and Williams, 2005).

Changes in temperature and salinity affect the saturation levels of DO in water, and thus incubation bottles are held in strictly controlled conditions designed to regulate light, temperature and salinity, and thereby isolate the effects of either community respiration or photosynthesis in the bottles (Dickinson et al., 2007). Researchers may incubate sealed bottles inside a temperature controlled water bath (Sampou and Kemp, 1994; Arístegui and Harrison, 2002; Williams et al., 2016), incubate bottles in situ at surface depths, or incubate the bottles in a temperature controlled room in the open air. These incubation techniques assume that no exchange of dissolved gasses occurs between the incubation water in the bottle and the surrounding environment, and much of this exchange can be reduced by greasing the ground glass caps with appropriate barriers (Dickinson et al., 2007).

In environments where the DO gradient between the incubation water and the surrounding incubation medium are similar, the amount of exchange between the incubation water and water bath is less likely to be significant. However, in strongly stratified systems (i.e., tropical lakes and estuaries, fjords, lochs, and fjord-like systems), with relatively low levels of DO saturation, a steep DO gradient is expected between the incubation water collected below the halocline of such systems and the traditional open air or flow-through water bath setup. Such a steep DO gradient makes these experiments especially prone to diffusion issues, and thus may render the results of such experiments misrepresentative of the actual environmental conditions. 
If diffusion driven DO exchange occurs between incubation water and a water bath it may lead to erroneously high respiration rates from water collected at the surface. This water may have a higher initial DO than the water bath due to photosynthetic activity saturating the water column before it was collected from the field. Likewise, there may be significant underestimation of respiration rates from water collected below the thermocline/halocline because this water can often be DO poor (especially if these waters have high residence times and/or experience high nutrient loading) and would diffuse into the bottle from the relatively $\mathrm{O}_{2}$ rich water bath used to maintain constant temperature. Bottles incubated at the surface of such system or in an open-air medium would experience similar issues.

We feel it is vital to highlight the potential for diffusion driven DO exchanges that can occur while measuring pelagic community respiration/ biological oxygen demand (BOD). This is especially pertinent given that many such systems (tropical lakes and estuaries, and fjords, lochs, and fjord-like systems) are home to expanding aquaculture activities whose impacts may be, in part, measured by trends in BOD and/or water column respiration. The purpose of this paper is to provide an easily employable quality control technique to identify and describe diffusion driven DO exchanges between the incubation water and incubation medium.

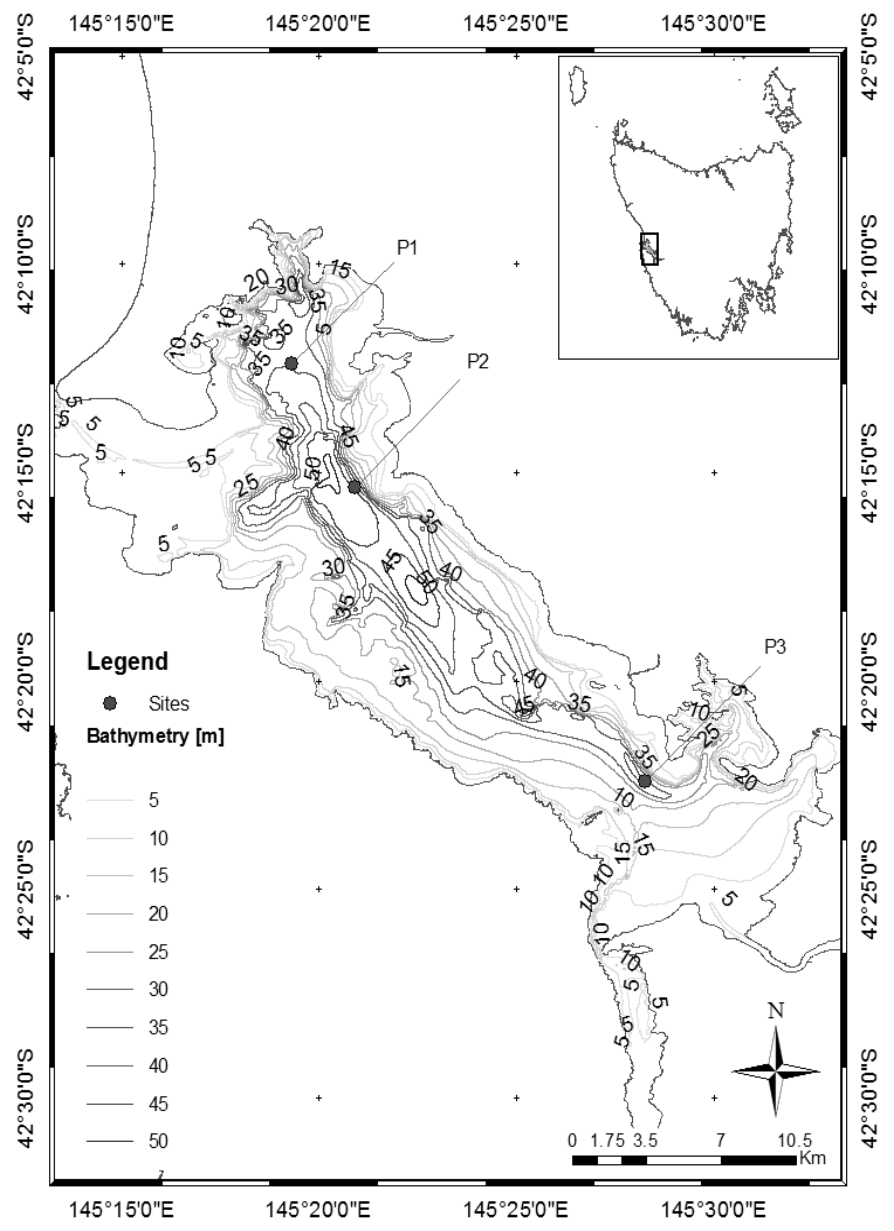

Figure 1. Map of Macquarie Harbour with Bathymetry

\section{Methods}

\section{Site description}

Macquarie Harbour is a model system where diffusion during bottle incubations may be significant enough to skew future measurements of respiration. It is a fjord-like estuary located in western Tasmania (Figure 1), where previous attempts to measure community respiration have suggested that this process occurs at relatively low rates (Figure 2)(Approx. $0.008 \mathrm{mg} \mathrm{O}_{2} \mathrm{~L}^{-1} \mathrm{H}^{-1}$ in summer; Revill et al., 2016) compared to other, more heavily impacted, estuaries such as Chesapeake Bay (from $0.04-0.08 \mathrm{mg} \mathrm{O}_{2} \mathrm{~L}^{-1} \mathrm{H}^{-1}$; Sampou and Kemp, 1994), San Francisco Bay (up to $0.038 \mathrm{mg} \mathrm{O}_{2} \mathrm{~L}^{-1} \mathrm{H}^{-1}$; Caffrey et al., 1998), and Roskilde Fjord (mean rates up to $0.0596 \mathrm{mg} \mathrm{O}_{2} \mathrm{~L}^{-1} \mathrm{H}-1$; Jensen et al., 1990). Macquarie Harbour has a strongly stratified water column due to high freshwater inflow, where concentrations of DO are often observed to be less than $2 \mathrm{mg} \mathrm{L}^{-1}$ below the halocline (Cresswell, 1989). It is home to extensive fish cage aquaculture, and has a relatively pristine catchment. Macquarie Harbour's water column DO profiles often show sharp declines below the halocline, and water samples collected at varying depths are also collected along gradients of various hydrographic parameters such as salinity, temperature, and importantly DO (Figure 3) (Cresswell, 1989; Carpenter et al., 1991; MHDOWG, 2015).

\section{Pelagic Respiration Rates in Various Estuaries}

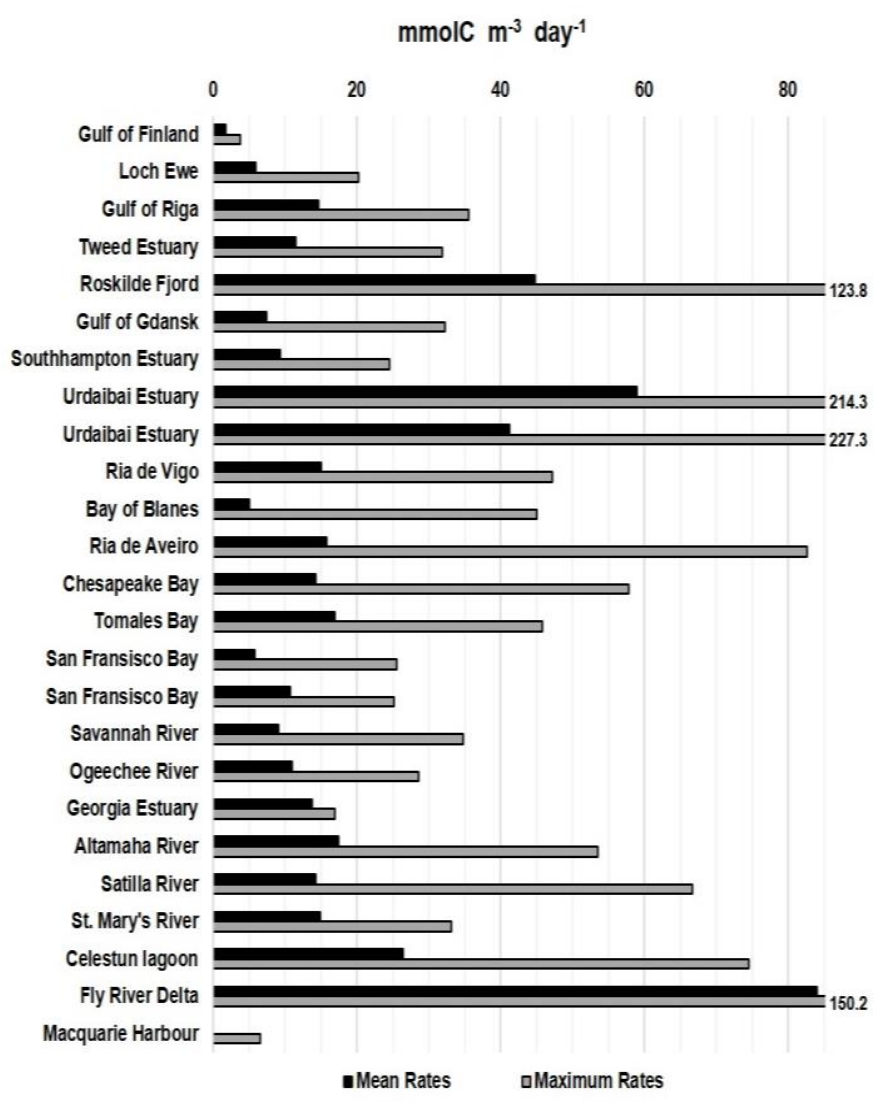

Figure 2. Maximum DO consumption rate measured in Macquarie Harbour to date (Revill et al., 2016) compared to other estuaries. Figure adapted from data presented in Hopkinson and Smith (2005) 

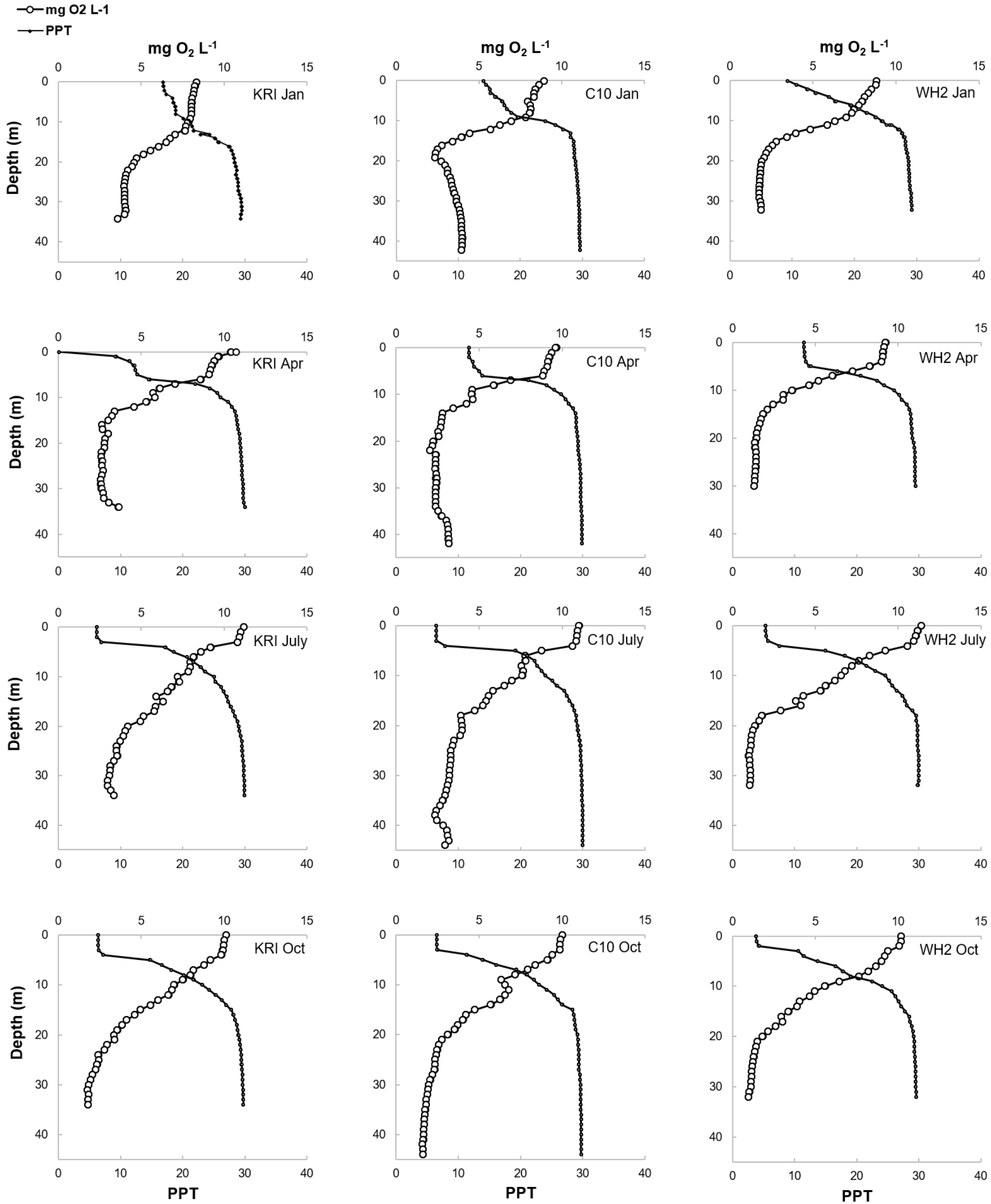

Figure 3. Seasonal dissolved oxygen and salinity profiles at three locations in Macquarie Harbour. Open circles represent dissolved oxygen concentrations in $\mathrm{mg} \mathrm{L}^{-1}$ and closed circles represent salinity in PPT 


\section{Experimental method to identify and describe diffusion}

DO diffusion was measured in a field research laboratory by incubating 60, pre-soaked ( 24 hours) $300 \mathrm{ml}$ borosilicate BOD bottles (FAVORIT ® brand PLT Scientific Sdn. Bhd.) with a freshwater source from the town of Strahan's local water supply. The Strahan water source is relatively well treated (using flocculation, filtration, $\mathrm{pH}$ adjustment, chlorination, and fluoridation techniques; Tasmania Annual Water Quality Report 2014-2015) and was not under a water quality alert during the time of this experiment (30 ${ }^{\text {th }}$ April 2016), and it is assumed that biological activity was not significant. Initially, $2 \mathrm{~L}$ polycarbonate carboys were filled with water and allowed to equilibrate in air until they reached the water bath temperature of $15^{\circ} \mathrm{C}$ before being sparged with a $97 \%$ helium gas ( $3 \%$ Air) mixture. Bubbling the incubation water in the $2 \mathrm{~L}$ container displaces other dissolved gasses and allows us to artificially drive down DO concentrations prior to filling the BOD bottles. The 2L carboy was then gently shaken to mix the water mass inside it. Three BOD bottles were then gently filled, and overflowed to displace any water contamination with air, through pre-soaked Tygon $₫$ tubing for each $2 \mathrm{~L}$ carboy prepared. DO concentrations were measured with a Hach IntelliCAL ${ }^{\mathrm{TM}}$ LD0101 optical DO probe. Initial DO concentrations inside the $60 \mathrm{BOD}$ bottles ranged from $2.51 \mathrm{mg} \mathrm{L}^{-1}$ to $10.03 \mathrm{mg} \mathrm{L}^{-1}$, and all the bottles were incubated in the dark for approximately 24 hours before DO was measured a second time. A recirculating artificial sea water bath (33 ppt) was used in lieu of a freshwater bath because the seawater has a lower DO concentration at $100 \%$ saturation than freshwater, and thus would allow us to observe DO diffusion both into and out of the bottles.

Diffusion is calculated as the change in concentration divided by incubation time. To quantify the role of diffusion in the total DO flux we used a correlation setting the total DO flux as a function of the DO concentration initially measured in the bottle. Since all bottles were incubated in the same water bath this is assumed to be the same as setting the change in DO as a function of the difference between the initial DO in the bottle and the DO of the water bath.

\section{Results and Discussion}

D0 flux rates ranged from $-0.012 \mathrm{mg} \mathrm{O}_{2} \mathrm{~L}^{-1}$ hour-1 to 0.005 $\mathrm{mg} \mathrm{O}_{2} \mathrm{~L}^{-1}$ hour-1 for bottles incubated with initial DO ranging from $10.03 \mathrm{mg} \mathrm{O}_{2} \mathrm{~L}^{-1}$ to $3.31 \mathrm{mg} \mathrm{O}_{2} \mathrm{~L}^{-1}$ respectively (Figure 4). The waterbath DO concentrations ranged from $7.8 \mathrm{mg} \mathrm{L}^{-1}$ to $8.3 \mathrm{mg} \mathrm{L}^{-1}$ during the incubation. A clear and statistically significant relationship was observed when DO flux was set as a function of initial DO (DO Flux $=-0.0017 \mathrm{x}+0.0085, \mathrm{r}^{2}=$ $0.72, \mathrm{p}<2.2 \mathrm{e}^{-16}$ ). When initial DO is low (i.e., lower than the water bath DO) the concentration of the oxygen in the bottle increased and the amount of increase was proportional to the DO difference between the water bath and incubated water. We have calculated the $95 \%$ confidence interval of the linear regression and have it shown in Figure 4. The confidence interval of the regression is not parallel with the regression line itself, due to the greater spread of the data in the lower range of initial DO. There are also some concerning data points that show a negative flux (DO entering the bottle) and have initial DO concentrations (values from 4.73 mg O $\mathrm{L}^{-1}$ to $4.92 \mathrm{mg} \mathrm{O}_{2} \mathrm{~L}^{-1}$ ) less than the water bath. It is possible that these could be erroneous values caused be either bubbles/ sealant grease on the probe tip or loose ground glass fittings. If future studies expect to incubate water with near-hypoxic DO concentrations (DO $<2.0 \mathrm{mg} \mathrm{L}-$ 1) we recommend including more diffusion blanks in this range to better capture the possible diffusive flux.

The relationships between initial DO concentration and DO flux in the diffusion data set above suggests diffusion can be a significant driver of DO exchange. Failing to test for and determine the amount of diffusion occurring in the experiment would risk reporting overestimated DO consumption for water collected above the halocline (waters there can experience both photosynthesis and wind mixing, and thus have relatively higher DO than the incubating water bath) and underestimated BOD (or even production) for water collected below the halocline. Environmental monitoring programs incorporating water column respiration or BOD measurements could potentially misrepresent the impacts activities, such as aquaculture, may have on the system.

Some attention has been paid to the effects of wastes derived from fish cage aquaculture on microbial process rates (as mentioned in Tett, 2008 and Price et al., 2015) and many monitoring programs do incorporate BOD measurements and thus would benefit from testing for diffusive flux when setting bottle incubations. The assumption diffusion has been prevented by applying sealant to the glass stopper and neck of the bottles (as mentioned in Dickson et al., 2007) needs to be tested during incubations, possibly by including a set of parallel diffusion blanks, as described in the methods above, with bottle incubations of site water when possible to test this assumption, especially in stratified systems.

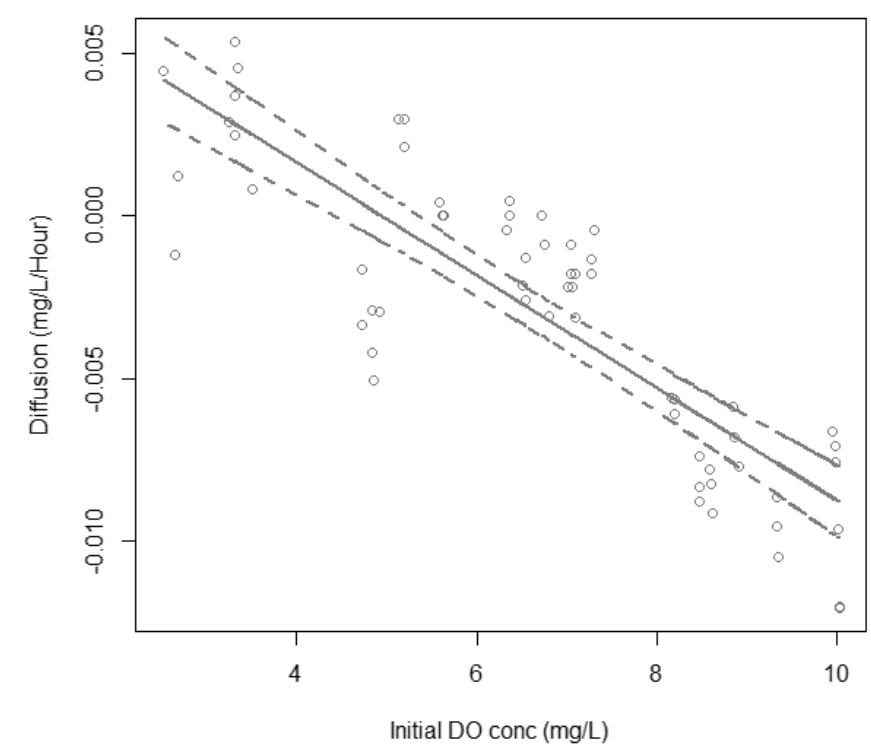

Figure 4. DO flux as a function of initial DO concentration in the incubation vessel. 
Some studies of microbial DO uptake do report respiration rates considered theoretically impossible such as oxygen production in the dark bottles (described in Williams, 2000 and Robinson and Williams, 2005). Perhaps the "impossible" rates from Williams (2000) and the data set mentioned in Robinson and Williams (2005) are due to dark oxygen generating processes like methanogenesis, however, few of those studies account for either diffusion or methanogenesis and would have benefitted from testing both phenomena.

\section{Acknowledgements}

We would like to acknowledge the Tasmania Institute of Marine and Antarctic Studies for the use of laboratory space and equipment as well as providing advice and guidance concerning this research.

\section{References}

Arístegui, J., \& Harrison, W. G. (2002). Decoupling of primary production and community respiration in the ocean: implications for regional carbon studies. Aquatic Microbial Ecology 29(2), 199-209.

Caffrey, J. M., Cloern, J. E., \& Grenz, C. (1998). Changes in production and respiration during a spring phytoplankton bloom in San Francisco Bay, California, USA: implications for net ecosystem metabolism. Marine Ecology Progress Series 172, 1-12.

Carpenter, P. D., Butler, E. C. V., Higgins, H. W., Mackey, D. J., \& Nichols, P. D. (1991). Chemistry of trace elements, humic substances and sedimentary organic matter in Macquarie Harbour, Tasmania. Marine and Freshwater Research 42(6), 625-654.

Cresswell, G. R., Edwards, R. J., \& Barker, B. A. (1989). Macquarie Harbour, Tasmania-seasonal oceanographic surveys in 1985. In Papers and Proceedings of the Royal Society of Tasmania 123, 63-66.

Del Giorgio, P. A., \& Williams, P. J. L. B. (Eds.). (2005). Respiration in Aquatic Ecosystems. Oxford University Press, USA.

Department of Primary Industries, Park, Water, and Environment. (2015) Macquarie Harbour Dissolved Oxygen Working Group (MHDOWG). Update $\quad 2015 . \quad$ Report from: http://dpipwe.tas.gov.au/Documents/MHR\%20\%20Dissolved\%200xygen \%20Working\%20Group\%20Update\%20Report\%20April\%202015.pdf 18 July 2017.

Diaz, R. J., \& Rosenberg, R. (2008). Spreading dead zones and consequences for marine ecosystems. Science 321(5891), 926-929.

Dickson, A. G., Sabine, C. L., \& Christian, J. R. (2007). Guide to best practices for ocean CO2 measurements. PICES Special Publication 3, IOCCP Report No.8.

Hopkinson, C.S. and Smith, E.M., 2005. Estuarine respiration: an overview of benthic, pelagic, and whole system respiration. Respiration in Aquatic Ecosystems, 122-146.

Jensen, L. M., Sand-Jensen, K., Marcher, S., \& Hansen, M. (1990). Plankton community respiration along a nutrient gradient in a shallow Danish estuary. Marine Ecology Progress Series 61(1), 75-85.

Price, C., Black, K.D., Hargrave, B.T. and Morris Jr, J.A., 2015. Marine cage culture and the environment: effects on water quality and primary production. Aquaculture Environment Interactions 6(2), 51-174.

Rabalais, N. N., Diaz, R. J., Levin, L. A., Turner, R. E., Gilbert, D., \& Zhang, J. (2010). Dynamics and distribution of natural and human-caused hypoxia. Biogeosciences, 7(2), 585-619.
Revill, A. T., Ross, J., \& Thompson, P. A. (2016). Investigating Dissolved Oxygen Drawdown in Macquarie Harbour. CSIRO, Australia. Report to Huon Aquaculture

Robinson, C. \&Williams, P.L.B., 2005. Respiration and its Measurement in Surface Marine Waters. Respiration in Aquatic Ecosystems, 147-180

Sampou, P., \& Kemp, W. M. (1994). Factors regulating plankton community respiration in Chesapeake Bay. Marine Ecology-Progress Series 110, 249-249.

Taswater 22-2-2016, Drinking Water Quality Report 2014-2015 version 2.3, viewed 11-07-2016, http://www.taswater.com.au/AboutUs/Publications

Tett, P. (2008) Fish farm waste in the ecosystem. In: Holmer, M, Black K, Duarte CM, Marba N, Karakassis I (eds) Aquaculture in the ecosystem. Springer, Dordrecht, P 1-46.

Valiela, I. (2013). Marine Ecological Processes. Springer Science \& Business Media.

Williams, P. L. B. (2000). Net production, gross production and respiration: what are the interconnections and what controls what. The Changing Ocean Carbon Cycle: A Midterm Synthesis of the Joint Global Ocean Flux Study. Cambridge University Press, Cambridge, 37-60. 